\title{
OZONE BACKGROUND LEVELS AND TRENDS IN THE STATE OF KUWAIT
}

\author{
MOHAMED F. YASSIN, MARIAM J. MALEK \& MUFREH S. AL-RASHIDI \\ Environment \& Life Sciences Center, Kuwait Institute for Scientific Research, Kuwait
}

\begin{abstract}
With the rapid of climate change, development of industrialization and urbanization in the world, the level of ozone $\left(\mathrm{O}_{3}\right)$ concentration in the atmosphere has become a serious problem causes adverse human health effects. Background $\mathrm{O}_{3}$ is defined as the fraction of the $\mathrm{O}_{3}$ present in a given area that is not attributed to anthropogenic sources of local origin. As such, background $\mathrm{O}_{3}$ has several welldocumented sources, both natural and anthropogenic. These include: (a) downward transport of stratospheric $\mathrm{O}_{3}$ through the free troposphere to near the ground level, (b) in situ $\mathrm{O}_{3}$ production from methane emitted from swamps and wetlands reacting with natural $\mathrm{NO}_{\mathrm{x}}$ (from soils, lightning strikes and downward transport of $\mathrm{NO}$ from the stratosphere), (c) in situ production of $\mathrm{O}_{3}$ from reactions of biogenic VOCs with natural $\mathrm{NO}_{\mathrm{x}}$ and (d) long-range transport of $\mathrm{O}_{3}$ from distant pollutant sources. In this study, we collected the $\mathrm{O}_{3}$ data from air quality monitoring stations for ten years in the state of Kuwait. The $\mathrm{O}_{3}$ status and trends were analysis by using the Open-Air Package. The background level of $\mathrm{O}_{3}$ assessed using the Kolmogorov-Zurbenko (KZ) filter technique. The result shows that the observed levels of $\mathrm{O}_{3}$ background concentrations were high in the urban site. The diurnal variations of $\mathrm{O}_{3}$ at different locations showed a similar trend.
\end{abstract}

Keywords: KZ filter, meteorological conditions, Open-Air Package, ozone, urban, suburban and rural environment.

\section{INTRODUCTION}

The ozone $\left(\mathrm{O}_{3}\right)$ is a toxic molecule to air quality, which located outside the ozone layer. Ozone cannot emit directly into the air so that a secondary pollutant names it because it was created by chemical reactions between oxides of nitrogen $\left(\mathrm{NO}_{\mathrm{x}}\right)$ and volatile organic compounds (VOC) in the presence of sunlight. It is also transported to the troposphere from the stratosphere. The $\mathrm{NO}_{\mathrm{x}}, \mathrm{VOC}$, and $\mathrm{CO}$ are signs of $\mathrm{O}_{3}$ have anthropogenic sources, including fuel combustion as well as natural sources, including lightning, wildfires, soils, and vegetation. Moreover, there are major sources for ozone emissions from industrial facilities and electric utilities, motor vehicle exhaust, gasoline vapors, and chemical. The KEPA hourly mean standard for $\mathrm{O}_{3}$ is $80 \mathrm{ppb}$, the 8 hourly rolling average standards for $\mathrm{O}_{3}$ is $60 \mathrm{ppb}$. Annual average ozone concentrations range between approximately 20-45 ppb, with variability being a function of geographic location, elevation and extent of anthropogenic influence through Hemisphere masses (Vingarzan [1]). The presence of the ozone has many impacts such as effects on the human health, which they are common in the summer season in Kuwait such as; respiratory problem, wheezing and breath problem, also breathing ozone can trigger a variety, particularly health problem for children, the elderly, and people at all ages who have lung diseases such as asthma. As well as it has a harmful effect of the environment such as damages in vegetation and problem in Kuwait's ecosystem and toxic, to grow certain crops (Fiore at al. [2]). Ozone formation at different elevations in a mountainous area of Hong Kong simulated by Wang et al. [3] using WRF-CMAQ model. Results showed that the simulated meteorological parameters and air pollutants were well in agreement with the observations. They found the positive contribution of vertical transport, including advection and diffusion to $\mathrm{O}_{3}$ mixing ratios at the two sites, suggesting that $\mathrm{O}_{3}$ values at lower locations could be affected by $\mathrm{O}_{3}$ at higher locations via vertical advection 
and diffusion over Hong Kong. Ahmadov at al. [4] used a regional-scale air quality model (WRF-Chem) to simulate high ozone $\left(\mathrm{O}_{3}\right)$ episodes during the winter of 2013 over the Uinta Basin (UB) in northeastern Utah, which is densely populated by thousands of oil and NG wells. The model results show a disproportionate contribution of aromatic VOCs to $\mathrm{O}_{3}$ formations relative to all other VOC emissions. Ground-level ozone $\left(\mathrm{O}_{3}\right)$ pollution has become one of the top environmental issues in Kuwait, especially in the densely populated regions nearly from the industrial region. Therefore, the goal of this study is to examine (i) the long-term trends of $\mathrm{O}_{3}$ concentrations over Kuwait; (ii) the background level of ozone concentration.

\section{METHODS AND MATERIALS}

\subsection{Site description}

In this study, the air-quality data were collected from three locations within the state of Kuwait. The state of Kuwait lies between latitudes $28^{\circ}$ and $31^{\circ}$ north and longitudes $46^{\circ}$ and $49^{\circ}$ east in the northeastern edge of the Arabian Peninsula at the far northwestern corner of the Arabian Gulf; the overall land area of Kuwait is $17,818 \mathrm{~km}^{2}$. Kuwait shares borders with Iraq to the north and Saudi Arabia to the south (see Fig. 1), in the south and west, Kuwait shares a long border of about 250 kilometers with Saudi Arabia. Iraq has bounded around $240 \mathrm{~km}$ on north and North-West and in the eastern Kuwait borders the Arabian Gulf with 195 kilometers of coast.

\subsection{Data collecting and analysis}

The meteorological data were collected from different air quality stations of KEPA located in Al-Mansoriya, Al-Jahra, and Al-Mutla for four consecutive years (2007, 2008, 2009 and 2010). Al-Mansouriya station (MN) located in Al-Mansouriya residential area on the roof of Al-Mansouriya clinic. The location considered as a typical urban site. Where pollutants can be registered at this site due to the presence of Doha power generation, heavy traffic at the center of Kuwait City, Al-Arabi club, the gas station which is located in the southern part, and the Sheraton round about in the northwestern of the Morocco high way. Al-Jahra Station (JH) located on the roof of Al-Jahra Hospital about 15 meters from the ground. The location considered as a typical suburban site where pollutants can be registered at this site due to Doha power generation located in the northeast side, and it is the main sources of pollution in this location, as well as Al-Jahra sewage treatment in the South. Al-Mutlaa Station (MT) considered as a typical rural site where pollutants can be registered at this site due to AlRaudhatain oil field located in the north-eastern region, it is one of the main sources of pollution in this area. On the west side, it is bounded by an army camping the South-eastern region.

\subsection{Theoretical model}

The Kolmogorov-Zurbenko (KZ) filter was used to calculate the $\mathrm{O}_{3}$ background concentration. The KZ filter is robust and nearly optimal. Because its operation is a simple moving average, the $\mathrm{KZ}$ filter performs well in a missing data environment, especially in multidimensional time and space where missing data can cause problems arising from spatial sparseness. KZ filter has two parameters that each has clear interpretations so that specialists in different areas can easily adopt it. Software implementations for time series longitudinal and spatial data have been developed in the popular statistical package $\mathrm{R}$ with OPENAIR 


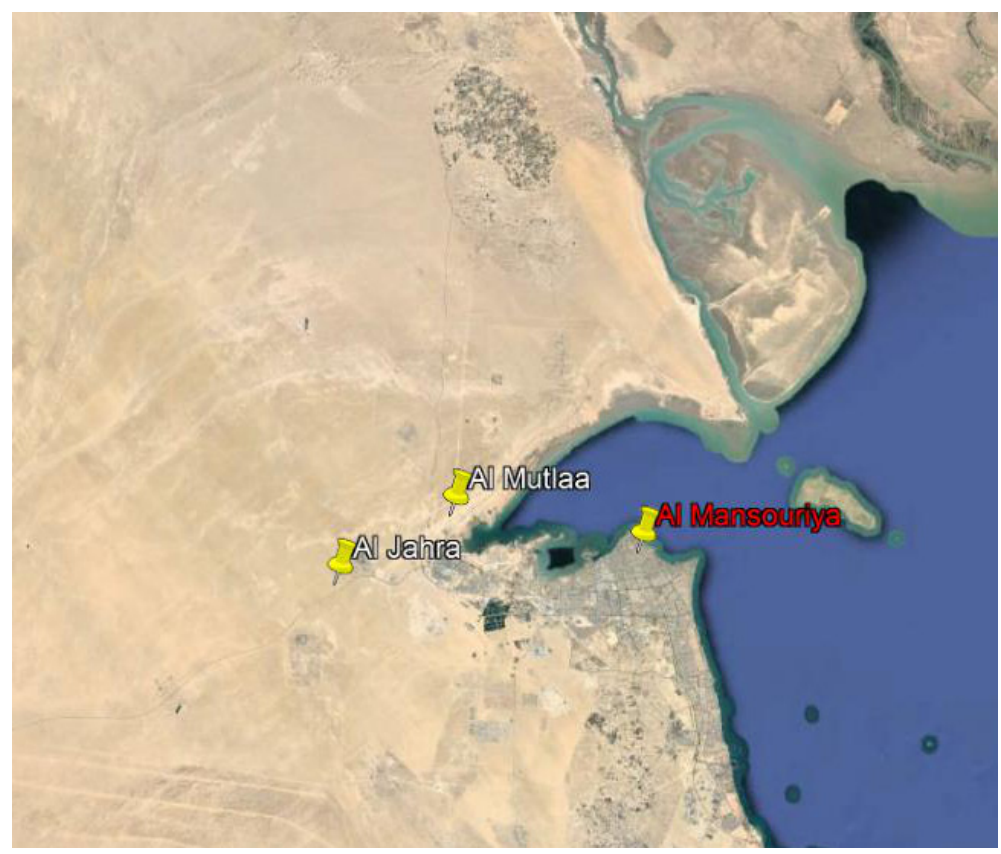

Figure 1: Site description of air quality stations.

code, which facilitates the use of the $\mathrm{KZ}$ filter and its extensions in different areas. STATISTICA-7 software was used to prepare the descriptive statistical analysis and calculate the percentage of exceeding of KEPA-AAQS.

\section{RESULTS AND DISCUSSIONS}

\subsection{Wind rose}

Fig. 2 shows the hourly recorded wind rose plot using the open-air code for the wind speed and direction over the years 2007-2010 at Al-Jahra (JH), Al-Mansouriya (MN) and AlMutala'a (MT) monitoring station, respectively. Fig. 2 provides that the main prevailing wind direction at Al-Jahra site be coming from the Northwesterly (NW) direction. Close inspection to Fig. 2, it can reveal that about $50 \%$ of the time (i.e. $35 \%+10 \%+5 \%$ ) the winds are blowing from the North to the west sector $(\mathrm{N}-\mathrm{W})$. The other $50 \%$ of the wind direction is coming from a different direction such as Northeast, East, Southeast, and Southwest, where at Al-Mansouriya site, around $50 \%$ of the time is coming from the Northwesterly (NW) direction. The other wind direction is divided as $10 \%$ from East, and around $8 \%-10 \%$ is from Southeast, the rest of is coming from west and southwest and at Al-Mutla'a site about $40 \%$ of the time is from Northwest. The other wind directions were around $20 \%$ of the direction were from West and southeast, 10\% is coming from east. The rest of winds are coming from South and Southwest. The overall predominant wind direction in Kuwait is the Northwesterly (NW) direction. It means that if there were any emission sources of pollutants upwind monitoring sites in Kuwait, most of the pollutants would be registered in the K-EPA. NW direction as it contributes about $40-50 \%$ of the time from such wind direction. It is conditional on the location of the emission sources and the location of the monitoring sites. 


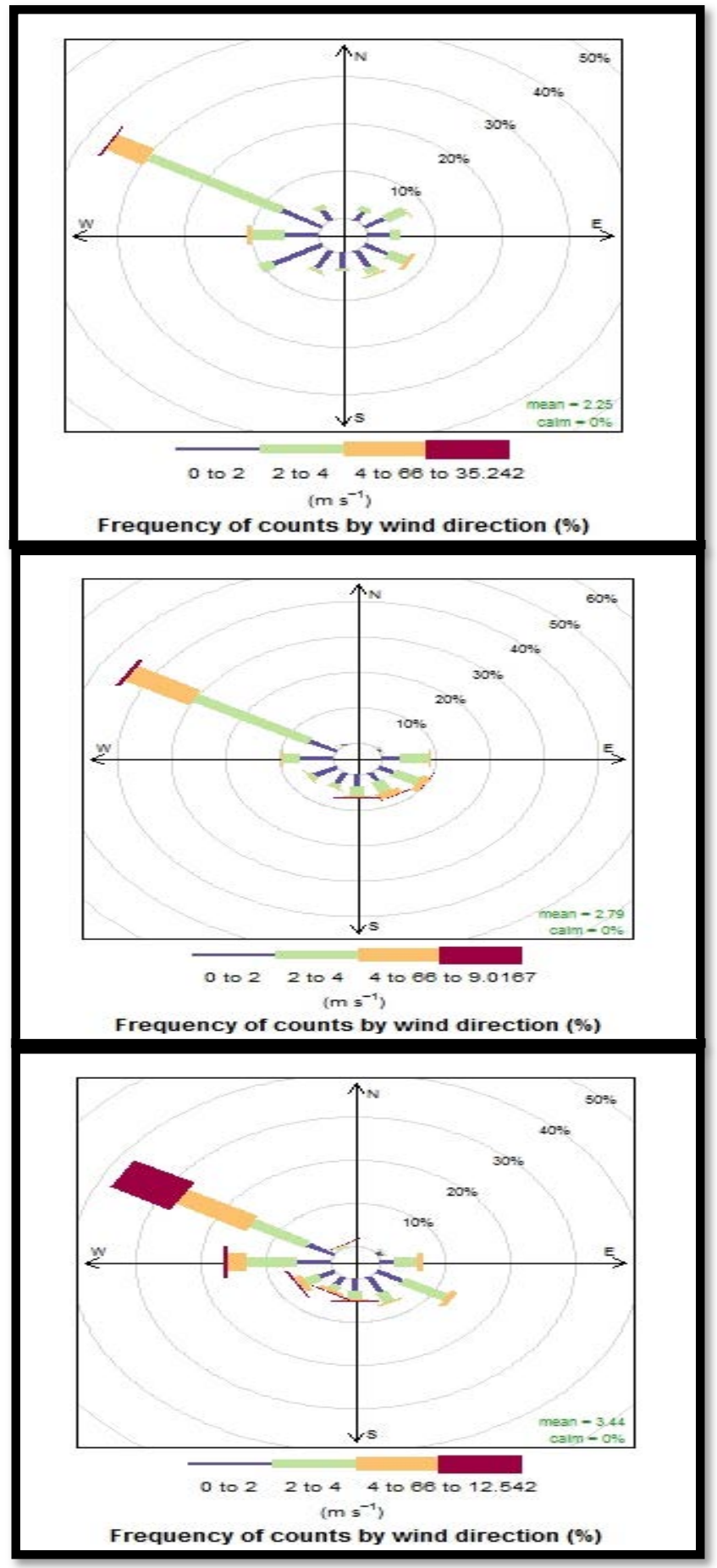

Figure 2: Hourly wind rose plot for the years 2007-2010 at three stations. 


\subsection{The diurnal variation}

Diurnal variation is the temporal distribution of pollutant concentrations over the 24 hours during the day. Fig. 3 shows the hourly concentration change in $\mathrm{O}_{3}$ at the three locations; the first location with the high trend for $\mathrm{O}_{3}$ concentration is Al-Mansouriya location, then the second one is Al-Mutla'a location, and the third one is Al-Jahra. In Al-Mutla'a location, the $\mathrm{O}_{3}$ concentration showed two peaks during the daytime, at 8 a.m. and 5 p.m. this increases might be from the activity in Al-Mansouriya site which is a crowded area and has higher traffic among the other station. Where, in Al-Roudtain oil field at Al-Mutla'a which is located about $20 \mathrm{~km}$ in the north direction from this station. The diurnal variation showed an earlymorning time peek; the $\mathrm{O}_{3}$ concentration is increased from 8 a.m. till 5 p.m. it is rising, and then it decreases from 6 p.m. to 7 p.m. and approximately to be stable. In Al-Jahra location, it is clear that the $\mathrm{O}_{3}$ concentration is an increase from 7 a.m. until 3 p.m. and possibly due to the emission of $\mathrm{O}_{3}$ from Al-Doha power plant as well as activities within the city at that time.

\subsection{Pollutant rose}

It shows that the higher concentrations are coming from the Northeasterly and Southeasterly 95-percentile from wind direction, as expected at this location where the Doha power plant which uses a high amount of fossil-fuel oil to support electricity to Kuwait. It also shows that higher concentrations occur for South winds, as expected at this location. However, the actual value of the 95-percentile of $\mathrm{O}_{3}$ concentration is coming from this direction. Moreover, it shows that higher concentrations occur for Southeast winds the other direction is the Northwest direction. Southeast may due to local sources and as expected at this location. However, it also shows, the actual value of the 95-percentile of $\mathrm{O}_{3}$ concentration is coming from this direction.

Table 1: The overall descriptive statistical analysis of the hourly concentration of the monitoring $\mathrm{O}_{3}$ pollutant.

\begin{tabular}{|l|c|c|c|}
\hline $\begin{array}{c}\text { Monitoring site } \\
\text { parameters }\end{array}$ & Al-Jahra & Al-Mansouriya & Al-Mutla'a \\
\hline Count no. & 27735 & 28139 & 14968 \\
\hline Mean & 18.9 & 21.9 & 21.4 \\
\hline Median & 15.3 & 21.1 & 20.7 \\
\hline Max. & 229 & 450 & 162 \\
\hline Min. & 0.1 & 0.0 & 0.0 \\
\hline Per. 5\% & 2.4 & 1.3 & 2.3 \\
\hline Per. 95\% & 45.8 & 45.8 & 43.3 \\
\hline Stdn. var. & 14.05 & 15.67 & 13.3 \\
\hline Exceededness & 0.08 & 0.3 & 0.31 \\
\hline
\end{tabular}




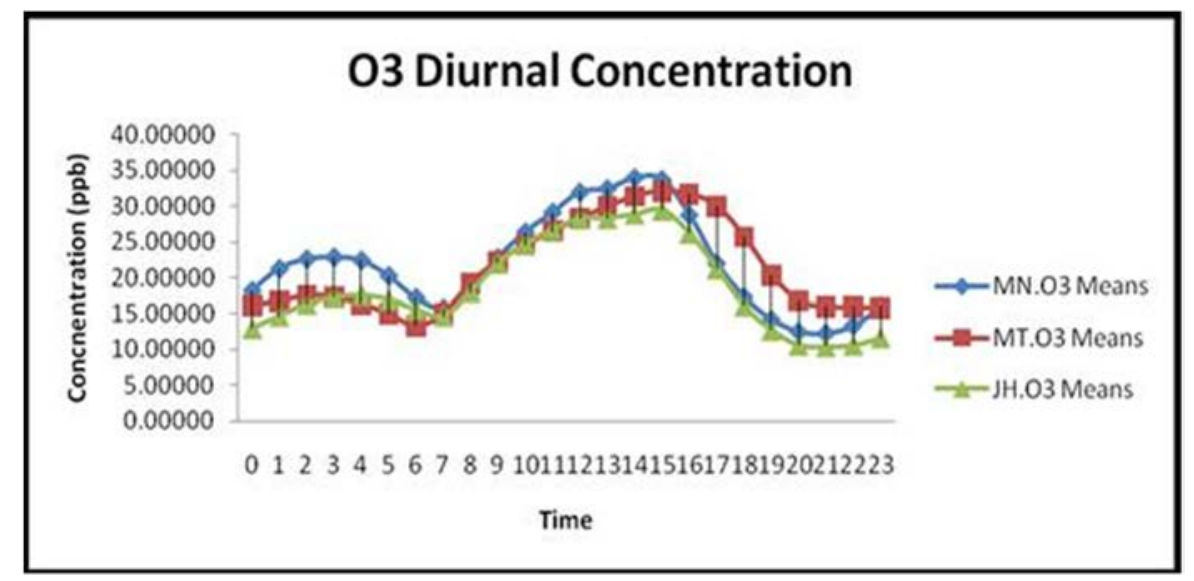

Figure 3: Diurnal variation of $\mathrm{O}_{3}$ concentration at the three locations.

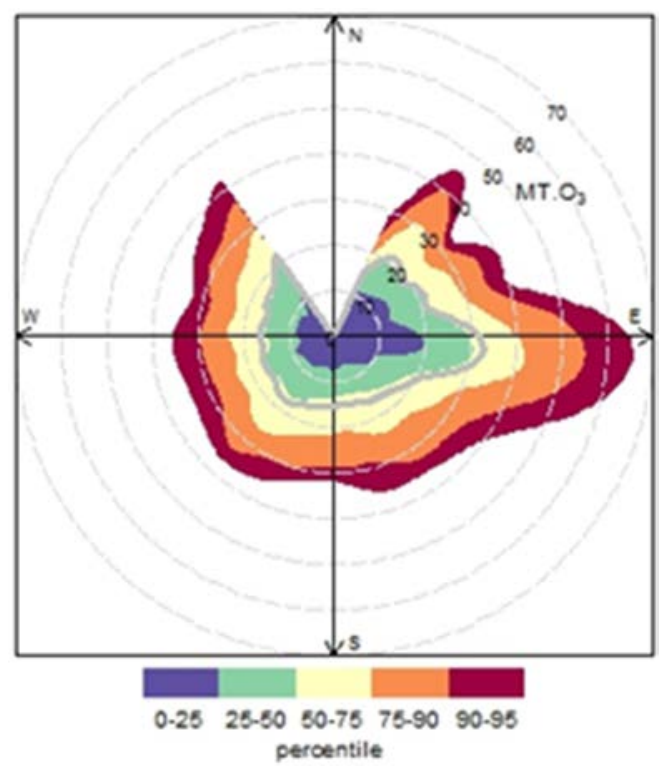

Figure 4: Percentile rose plot for $\mathrm{O}_{3}$ in Al-Jahra location.

\subsection{Kolmogorov Zurbenko (KZ) filtering}

In this study, the used filter parameters $(\mathrm{m}, \mathrm{k})$ is set as $(103,5)$ based on the recommendation of Hogrefe et al. [5] to calculate the $\mathrm{CB}(\mathrm{t})$ which corresponds to the baseline components and are used to compare the general background Locations (Al-Jahra, Al-Mansouriya, and AlMutla'a) concentration for the three locations in Kuwait. The separation point between two frequencies the low frequency (baseline) and the high frequency (short-term) component; is mainly governed by the filter parameters $\mathrm{m}$ and $\mathrm{k}$. As seen in this Fig. 7 the overall background concentrations for $\mathrm{O}_{3}$ at three locations were ranged between 15.0 to $15.8 \mu \mathrm{g} / \mathrm{m}^{3}$ 
in Al-Jahra, 20 to $25 \mu \mathrm{g} / \mathrm{m}^{3}$ in Al-Mansouriya, and 17.8 to $18 \mu \mathrm{g} / \mathrm{m}^{3}$ in Al-Mutla'a. Where, previously in Fig. 2, it can be seen that diurnal variation of $\mathrm{O}_{3}$ were ranged between 10 to 25 $\mathrm{ppb}$ in Al-Jahra, 15 to $35 \mathrm{ppb}$ in Al-Mansouriya, and 15 to $30 \mathrm{ppb}$ in Al-

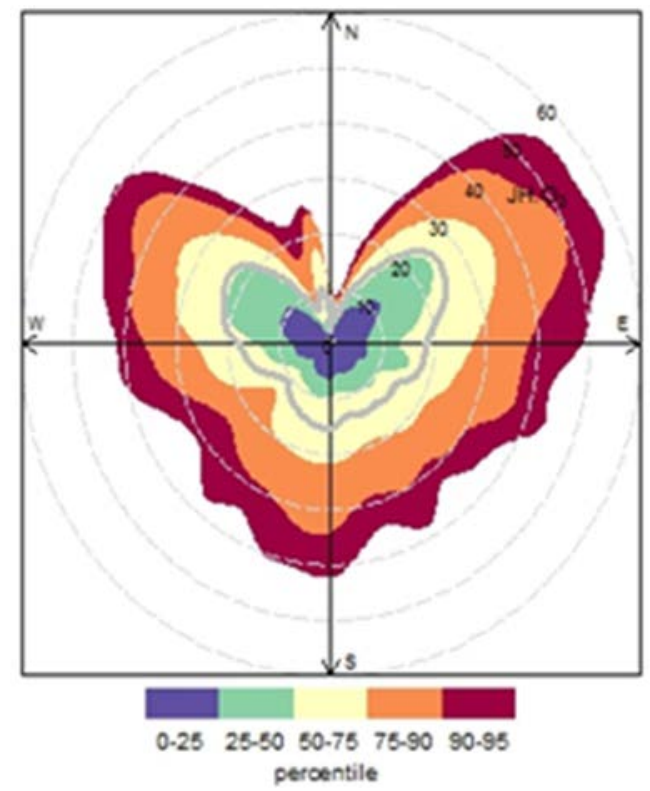

Figure 5: Percentile rose for $\mathrm{O}_{3}$ at Al-Mansouriya location.

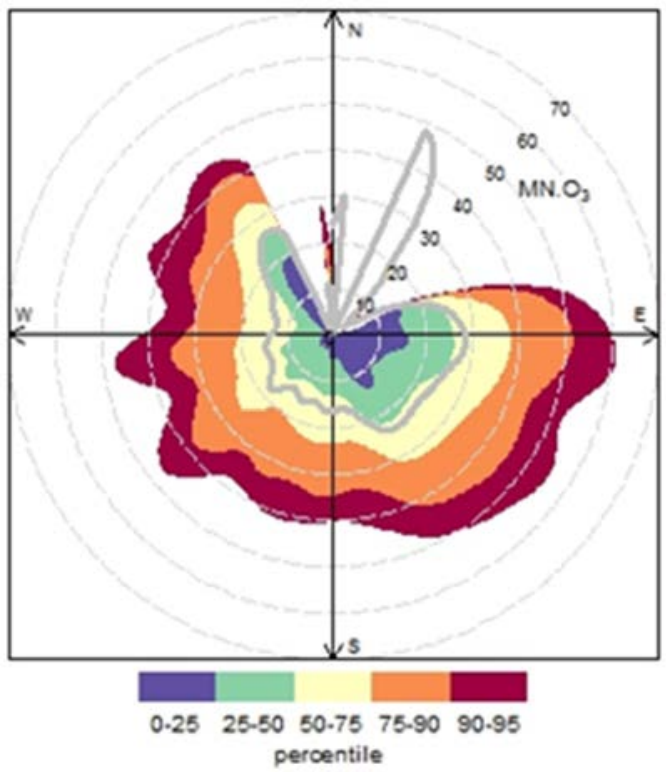

Figure 6: Percentile rose for $\mathrm{O}_{3}$ at Al-Mutla'a location. 

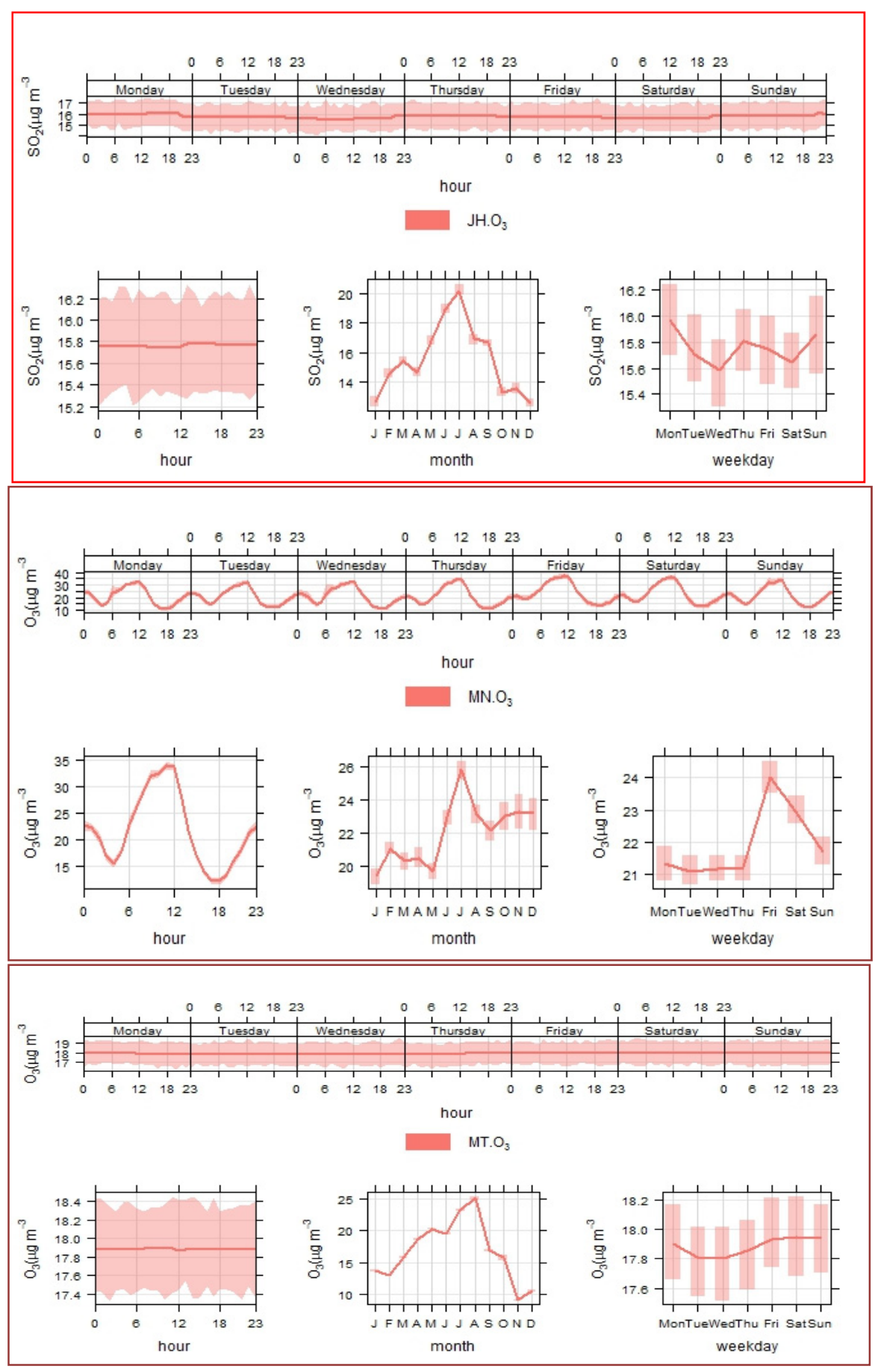

Figure 7: Time variation plots for the $\mathrm{O}_{3}$ background concentration at three locations. 
Mutla'a. Therefore, it can be noted that the diurnal variation that involves the short-term effects of local sources were eliminated and kept only the seasonal effects for the changes of the pollutants due to the changes in the cyclic meteorology. This is clearly shown in the monthly background concentrations of $\mathrm{O}_{3}$ at three locations, which provide that the concentration of $\mathrm{O}_{3}$ reach it is highest in summer and lowest in the wintertime.

\section{CONCLUSIONS}

The following conclusions of the study are :

- The ozone $\left(\mathrm{O}_{3}\right)$ molecule is a secondary pollutant that cannot be emitted directly into the air, which created by chemical reactions between oxides of nitrogen $\left(\mathrm{NO}_{\mathrm{x}}\right)$ and volatile organic compounds (VOC) in the presence of sunlight.

- The background concentration of $\mathrm{O}_{3}$ was $15.0-15.8 \mu \mathrm{g} / \mathrm{m}^{3}$ in Al-Jahra, 20-25 $\mu \mathrm{g} /$ Al-Mansouriya and $17.8-18 \mu \mathrm{g} / \mathrm{m}^{3} \mathrm{ppb}$ in Al-Mutla'a.

- The background concentration can be affected by metrological conditions, the human activity, traffic movement, and by burning fossil fuel from the power station and oil field.

- Summer season recorded the highest background concentration in the three locations among other seasons.

- This paper can be the core foundation for many future studies in the field of background concentration pollutant in Kuwait.

\section{REFERENCES}

[1] Vingarzan, R., A review of surface ozone background levels and trends. Atmospheric Environment, 38(21), pp. 3431-3442, 2004.

[2] Fiore, A., Jacob, D.J., Liu, H., Yantosca, R.M., Fairlie, T.D. \& Li, Q., Variability in surface ozone background over the United States: Implications for air quality policy. Journal of Geophysical Research: Atmospheres D, 24, p. 108, 2003.

[3] Wang, N., Guo, H., Jiang, F., Ling, Z.H. \& Wang, T., Simulation of ozone formation at different elevations in mountainous area of Hong Kong using WRF-CMAQ model. Science of the Total Environment, 505, pp. 939-951, 2015.

[4] Ahmadov, R. et al., Understanding high wintertime ozone pollution events in an oil-and natural gas-producing region of the western US. Atmospheric Chemistry and Physics, 15(1), pp. 411-429, 2016.

[5] Hogrefe, C., Rao, S.T., Zurbenko, I.G. \& Porter, P.S., Interpreting the information in ozone observations and model predictions relevant to regulatory policies in the eastern United States. Bulletin of the American Meteorological Society, 81(9), pp. 2083-2106, 2000 . 